Jurnal Akuntansi dan Manajemen

Vol.15, No.1, 2020, Hal.1-17

\title{
Analisis Pengambilan Keputusan Taktis: Tetap Mempertahankan Koran Cetak atau Mengganti ke Media Online
}

\author{
Ulfi Maryati' ${ }^{1}$ Kurniawati Putri², Armel Yentifa ${ }^{3}$, Dita Maretha Rissi ${ }^{4}$ \\ 1Jurusan Akuntansi, Politeknik Negeri Padang \\ Email:ulfimaryati@gmail.com \\ 2Jurusan Akuntansi, Politeknik Negeri Padang \\ Email: kurniawatiputri3@gmail.com \\ 3Jurusan Akuntansi, Politeknik Negeri Padang \\ Email: armelyentifa@gmail.com \\ ${ }^{4}$ Jurusan Akuntansi, Politeknik Negeri Padang \\ Email: ditamaretharissi@gmail.com
}

\begin{abstract}
ABSTRAK
Pembaca koran cetak mulai menurun seiring perkembangan teknologi, dan pembaca media online meningkat. Perusahaan koran cetak harus mengambil keputusan apakah tetap mempertahankan koran cetak atau mengganti ke media online. Penelitian ini merupakan penelitian terapan secara kuantitatif dengan menggunakan pendekatan studi kasus. Teknik pengumpulan data yang digunakan adalah wawancara, observasi dan dokumentasi. Penelitian ini menggunakan data primer, metode analisis yang digunakan adalah analisis tematik, langkah-langkah pengambilan keputusan taktis Hanse Mowen, dan teori rasional model. Hasil penelitian menunjukkan bahwa mengganti ke media online lebih menguntungkan ke depannya bagi perusahaan, karena media online tidak mengeluarkan biaya sebesar koran cetak. Media online tidak membutuhkan tinta, kertas, dan kendaraan operasional seperti koran cetak.
\end{abstract}

Kata kunci: Keputusan Taktis, Keep or Drop, Koran Cetak, Media Online, Biaya Relevan

\begin{abstract}
Printed Newspaper readers began to decline with development of technology, and online media readers increased. Printed newspaper companies must take a decision whether to keep the printed newspaper or change to online media. This research is a quantitative applied research using a case study approach. Data collection techniques used were interviews, observation and documentation. This study uses primary data, the analytical method used is thematic analysis, Hansen Mowen's tactical decision making steps, and rational theory models. The results of this research that switching to online media is more profitable going forward for companies, because online media do not cost as much as printed newspapers. Online media does not require ink, paper and operational vehicles such as print newspapers.
\end{abstract}

Keywords: Tactical decision, Keep or Drop, Printed Newspapers, Online Media, Relevant Costs

\section{Pendahuluan}

Eksistensi media cetak mulai berkurang dengan adanya era digital saat ini. Perkembangan teknologi membuat masyarakat cenderung lebih memilih mendapatkan informasi dari media online. Hal ini disebabkan karena orang-orang lebih menikmati membaca lewat media online daripada media cetak. Adanya 
peralihan era digital membuat minat pembaca media cetak menurun. Ketua Dewan Pers Indonesia mengungkapkan bahwa jumlah pembaca media cetak turun 30 persen, pendengar radio turun 10 persen, penikmat televisi naik 200 persen, sedangkan pembaca media online meningkat 500 persen. Hal ini diungkapkan oleh Ketua Dewan Pers Indonesia pada saat menghadiri Rakernas I Serikat Media Siber Indonesia (SMSI) di Surabaya, (Piliang, 2017).

Di Indonesia sudah banyak media cetak yang telah menutup perusahaannya, seperti yang diberitakan oleh Merdeka.com dengan judul Media Cetak Indonesia Bertumbangan, Ada Indikasi Sindrom Menular. Tutupnya Harian Sinar Harapan per 1 Januari 2016, mengonfirmasi masalah serius yang membetot bisnis media di Indonesia. Sebelum koran sore itu gulung tikar, beberapa perusahaan lain sudah menutup sebagian lini cetaknya dalam dua bulan terakhir, seperti The Jakarta Globe Koran Tempo Minggu, maupun Harian Bola. Direktur Eksekutif Serikat Perusahaan Pers (SPS) Indonesia, Asmono Wikan, menyatakan perkembangan teknologi cuma salah satu faktor yang mempengaruhi kondisi media cetak. Masyarakat perlahan lebih rutin mengakses informasi lewat internet, termasuk berita. Pengamat media dari Lembaga Studi Pers dan Pembangunan, Ignatius Haryanto mengatakan remaja sekarang lebih ingin membaca media online dibanding membaca koran (Prihatin, 2015).

Tidak hanya di Indonesia, Amerika Serikat pun juga ada banyak perusahaan media cetak yang menutup bisnisnya karena pengaruh era digital. Selain menutup bisnisnya karena sudah mulai menurunnya minat pembaca media cetak, ada juga yang beralih dari media cetak ke media online agar perusahaan yang telah dibangunnya tetap eksis di pasaran. Seperti yang diberitakan oleh Tempo pada tahun 2015, ada beberapa perusahaan di Amerika yang melakukan penutupan usahanya dan ada juga yang beralih ke media online. Seperti surat kabar Tribune Co yang mengajukan pailit pada tahun 2008 karena kurangnya pendapatan atas iklan, dan beralih ke media online. Ada juga Majalah Reader's Digest, perjuangannya harus berakhir pada pertengahan Februari 2013 lalu. Reader's Digest memilih untuk melayani pembacanya melalui edisi online (Dharapak, 2013).

Beberapa perusahaan lebih memlilih untuk beralih ke media online agar tetap bertahan di pasaran. Fenomena yang terjadi membuat manajemen perusahaan media cetak harus membuat keputusan apakah tetap mempertahankan koran cetak atau mengganti ke media online. Menurut Siregar dkk (2013) proses pengambilan keputusan adalah hal yang sangat penting bagi perusahaan. Manajemen perusahaan media cetak harus melakukan suatu analisis yang relevan agar pengambilan keputusan yang dilakukan tidak salah, manajemen dapat menganalisa biaya yang dihasilkan oleh perusahaan ketika tetap mempertahankan memproduksi koran atau beralih ke media online.

Manajemen perusahaan juga harus menganalisa dari sisi pendapatan yang dihasilkan oleh perusahaan ketika masih tetap bertahan di media cetak dan pendapatan yang akan didapatkan ketika perusahaan ingin beralih ke media online. Ketika ingin mengambil keputusan untuk beralih ke media online tentu akan ada pendapatan yang hilang dari penjualan koran dan biaya baru yang akan muncul nantinya karena beralih ke media online. Perusahaan harus bisa menganalisa hal seperti itu, agar ketika mengambil suatu keputusan, seperti ingin beralih ke media online pendapatan yang hilang dari penghentian penjualan koran tidak mempengaruhi keberlangsungan hidup perusahaan. Penelitian yang dilakukan 
terbatas pada masalah penerapan biaya relevan untuk pengambilan keputusan tetap mempertahankan memproduksi koran cetak atau mengganti ke media online. Penelitian ini menggunakan teknik pengumpulan data dengan wawancara dan observasi, hal ini berguna agar peneliti dapat menggali lebih dalam lagi faktor-faktor kualitatif yang ada pada penerapan analisis biaya relevan.

\section{Tinjauan Pustaka}

\section{Pengambilan Keputusan Taktis}

Pengambilan keputusan taktis yang tepat adalah keputusan yang dibuat tidak hanya mencapai tujuan terbatas, tetapi juga berguna untuk jangka panjang (Hansen dan Mowen, 2009). Tujuan dari pengambilan keputusan strategis adalah memilih strategi alternatif sehingga keunggulan bersaing jangka panjang dapat tercapai. Enam langkah pengambilan keputusan taktis menurut Hansen dan Mowen adalah sebagai berikut:

1. Definisikan Masalah

2. Identifikasi Beberapa Alternatif

3. Identifikasi Biaya dan Manfaat yang Berkaitan Dengan Setiap Alternatif yang Layak

4. Hitung Total Biaya dan Manfaat yang Relevan untuk Setiap Alternatif yang Layak

5. Nilai Faktor-Faktor Kualitatif

6. Membuat Keputusan

\section{Biaya Relevan}

Hansen dan Mowen (2009), menyatakan bahwa biaya relevan adalah biaya masa depan yang berbeda pada setiap alternatif. Ada beberapa konsep-konsep biaya dalam penerapan pengambilan keputusan. Biaya tambahan (incremental cost) yaitu kenaikan atau tambahan biaya yang akan terjadi karena memilih suatu alternatif. Biaya tenggelam (sunk cost) adalah biaya yang telah terjadi dan tidak dapat diubah oleh suatu keputusan yang dibuat sekarang atau pada masa yang akan datang. Sementara itu, biaya terhindarkan (avoidable cost) adalah suatu biaya yang dapat dihilangkan seluruhnya atau sebagian akibat dari pemilihan satu alternatif dalam suatu pengambilan keputusan (Samryn, 2002).

\section{Teori Rasional Model}

Manajer yang rasional melihat asumsi bahwa seorang pengambil keputusan yang rasional dengan informasi yang lengkap. Proses pengambilan keputusan yang rasional terdiri dari beberapa langkah sebagai berikut (Simon, 1977) dalam Turpin (2004):

1. Intelligence: menemukan kesempatan untuk membuat keputusan.

2. Design: menemukan, mengembangkan dan menganalisis kemungkinan jalurjalur untuk melakukan tindakan.

3. Choice: memilih jalur tertentu untuk melakukan tindakan dari alternatif yang tersedia

4. Review: menilai pilihan-pilihan yang lalu.

Berdasarkan teori rasional model, proses pengambilan keputusan taktis dapat dilakukan melalui 6 tahap sebagai berikut (Schoenfeld, 2011) dalam According to the 
rational model, the decision making process can be broken down into six steps (Schoenfeld, 2011) dalam (Lunenburg, 2010):

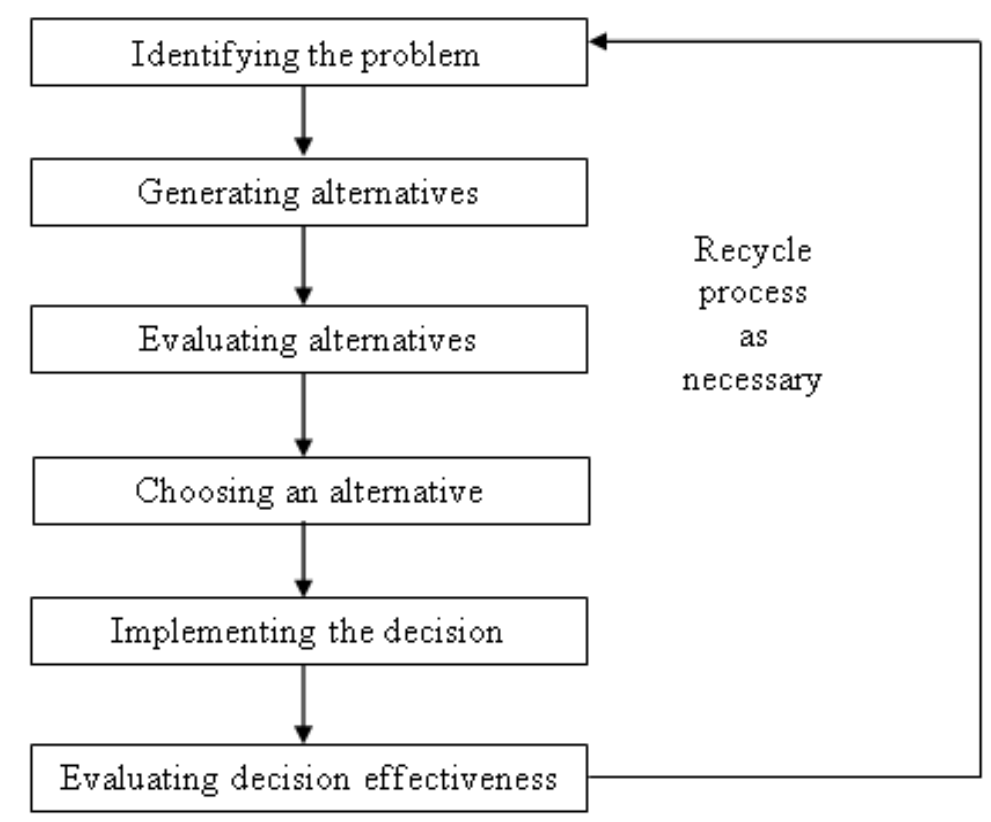

Gambar 1. Proses pengambilan keputusan taktis

\section{Metode Penelitian}

Penelitian ini merupakan penelitian terapan secara kuantitatif dengan menggunakan pendekatan studi kasus. Penelitian ini akan menggambarkan secara deskriptif analisis biaya, pengambilan keputusan taktis dan faktor-faktor non keuangan dari sisi manajemen (perusahaan). Sumber data yang digunakan pada penelitian ini adalah data primer. Sementara itu, teknik pengumpulan data yang digunakan adalah wawancara, observasi dan dokumentasi. Peneliti menggunakan teknik wawancara semi terstruktur dimana pertanyaan penelitian akan berkembang sesuai dengan jawaban narasumber. Metode analisis yang digunakan pada penelitian ini menggunakan analisis tematik, langkah-langkah pengambilan keputusan taktis Hansen Mowen, dan teori rasional model.

\section{Hasil dan Pembahasan}

\section{Identifikasi Masalah}

Penurunan minat baca masyarakat terhadap media cetak memiliki pengaruh terhadap penghasilan perusahaan media cetak. Masyarakat lebih memilih mendapatkan informasi dari media online dibandingkan dengan media cetak. Tidak hanya minat yang turun akan tetapi masyarakat mulai beralih ke media online. Harian Umum X saat ini memproduksi koran cetak dan menjalankan media online. Pendapatan media online yang diperoleh Harian Umum X masih lebih kecil dibandingkan dengan koran cetak. Pendapatan iklan online gratis sebesar Rp. 60.000.000, sementara pendapatan iklan koran cetak sebesar Rp. 3.600.000.000. 


\section{Identifikasi Beberapa Alternatif Keputusan}

Metode identifikasi untuk merumuskan alternatif-alternatif keputusan berdasarkan teori rasional model. Alternatif yang dapat diidentifikasi oleh Harian Umum X ada 3 yaitu:

a. Mempertahankan koran cetak tanpa media online

b. Menghentikan koran cetak dan mengganti ke media online

c. Mempertahankan koran cetak dan meneruskan media online

\section{Identifikasi Biaya dan Manfaat}

Identifikasi biaya dan manfaat akan dilakukan berdasarkan setiap alternatif keputusan. Pada tahap ini juga akan dipilah biaya yang relevan dan tidak relevan. Biaya yang tergolong relevan akan digunakan untuk pertimbangan keputusan, sedangkan biaya yang tidak relevan akan dieliminasi.

\section{a. Koran Cetak}

Adapun biaya koran cetak yang dikeluarkan oleh perusahaan selama satu tahun adalah sebagai berikut:

\begin{tabular}{clrr}
\multicolumn{4}{c}{ Tabel 1. Biaya Produksi Koran } \\
\hline \multicolumn{1}{c}{ Keterangan } & \multicolumn{1}{c}{ Jumlah } \\
\hline Biaya Bahan Baku Langsung : & $\mathrm{Rp}$ & 3.395 .520 .000 \\
1 & Biaya Kertas & $\mathrm{Rp}$ & 179.550 .000 \\
2 & Biaya Tinta Hitam & $\mathrm{Rp}$ & 65.664 .000 \\
3 & Biaya Tinta Giant & $\mathrm{Rp}$ & 58.752 .000 \\
4 & Biaya Tinta Yellow & $\mathrm{Rp}$ & 58.752 .000 \\
5 & Biaya Tinta Magenta & & \\
Biaya Overhead Pabrik : & $\mathrm{Rp}$ & 16.800 .000 \\
1 & Pengawet Koran & $\mathrm{Rp}$ & 685.440 .000 \\
2 & Seng Plat & $\mathrm{Rp}$ & 10.800 .000 \\
3 & Biaya Bongkar Bahan Baku & $\mathrm{Rp}$ & 60.000 .000 \\
4 & Biaya Honor Tulisan & $\mathrm{Rp}$ & 201.600 .000 \\
5 & Biaya Gaji Reparasi dan Pemeliharaan & $\mathrm{Rp}$ & 3.501 .132 .000 \\
6 & Biaya Gaji Bagian Produksi & $\mathrm{Rp}$ & 7.784 .000 \\
7 & Biaya Servis AC & $\mathrm{Rp}$ & 265.287 .354 \\
8 & Biaya Listrik Bagian Produksi & $\mathrm{Rp}$ & 596.279 .125 \\
\hline 9 & Biaya Penyusutan Aset Tetap & $\mathrm{Rp}$ & $\mathbf{9 . 1 0 3 . 3 6 0 . 4 7 9}$ \\
\hline \multicolumn{2}{c}{ Jumlah } & \multicolumn{3}{c}{}
\end{tabular}

Sumber: perusahaan (data diolah)

Perusahaan membutuhkan kertas sebanyak 720 rol selama satu tahun. Kertas dibeli dengan harga Rp. 12.000 per kg, 1 rol kertas memiliki berat sebesar $393 \mathrm{~kg}$. Bahan baku yang digunakan oleh perusahaan selain kertas adalah tinta. Ada 4 jenis tinta yang digunakan dalam memproduksi koran diantaranya yaitu: tinta hitam, tinta giant, tinta yellow, dan tinta magenta. Tinta hitam dibutuhkan sebanyak $5.400 \mathrm{~kg}$ selama satu tahun, harga tinta hitam Rp. 6.650 .000 untuk berat $200 \mathrm{~kg}$. Tinta giant, tinta yellow dan tinta magenta dibutuhkan untuk produksi sebanyak $4.320 \mathrm{~kg}$ selama satu tahun. Harga tinta giant untuk berat $5 \mathrm{~kg}$ adalah sebesar Rp. 76.000 sementara untuk tinta yellow dan magenta masing-masing harganya sebesar Rp. 68.000 untuk berat $5 \mathrm{~kg}$. 


\section{b. Media Online}

Adapun biaya yang dikeluarkan oleh perusahaan untuk media online adalah sebagai berikut:

Tabel 2. Biaya Media Online

\begin{tabular}{llr}
\hline \multicolumn{1}{c}{ Keterangan } & \multicolumn{2}{c}{ Jumlah } \\
\hline Biaya sewa hosting & $\mathrm{Rp}$ & 1.500 .000 \\
Biaya sewa domain & $\mathrm{Rp}$ & 500.000 \\
Biaya Internet & $\mathrm{Rp}$ & 6.000 .000 \\
Biaya Listrik Media Online & $\mathrm{Rp}$ & 16.078 .021 \\
Biaya Gaji Media Online & $\mathrm{Rp}$ & 3.295 .980 .000 \\
Biaya Servis AC & $\mathrm{Rp}$ & 5.189 .333 \\
Biaya Honor Tulisan & $\mathrm{Rp}$ & 60.000 .000 \\
Biaya Amortisasi Aset Tak Berwujud & $\mathrm{Rp}$ & 7.500 .000 \\
Biaya Penyusutan Aset Tetap & $\mathrm{Rp}$ & 51.079 .250 \\
\hline Total Biaya & $\mathrm{Rp}$ & $\mathbf{3 . 4 4 3 . 8 2 6 . 6 0 5}$ \\
\hline
\end{tabular}

Sumber: perusahaan (data diolah)

Perusahaan mengeluarkan biaya sewa hosting dan domain selama satu tahun adalah sebesar Rp. 1.500 .000 dan Rp. 500.000. Hosting merupakan sebuah tempat atau ruangan yang digunakan untuk menyimpan berbagai data dalam sebuah website. Sementara itu, domain adalah nama unik yang diberikan untuk mengidentifikasi alamat (IP address) server komputer seperti web server atau email server di internet.

\section{c. Biaya Pemasaran dan Biaya Administrasi dan Umum}

Adapun biaya pemasaran dan biaya administrasi umum yang dikeluarkan oleh perusahaan selama satu tahun adalah sebagai berikut:

Tabel 3. Biaya Pemasaran dan Administrasi Umum

\begin{tabular}{|c|c|c|c|}
\hline \multicolumn{2}{|r|}{ Keterangan } & \multicolumn{2}{|r|}{ Jumlah } \\
\hline \multicolumn{4}{|c|}{ Biaya Pemasaran : } \\
\hline 1 & Biaya Bahan Bakar & $\mathrm{Rp}$ & 696.000 .000 \\
\hline 2 & Biaya servis kendaraan & $\mathrm{Rp}$ & 108.000 .000 \\
\hline 3 & Biaya gaji dan tunjangan bag. Pemasaran & $\mathrm{Rp}$ & 381.420 .000 \\
\hline 4 & Pajak Kendaraan & $\mathrm{Rp}$ & 8.985 .000 \\
\hline 5 & Biaya distribusi koran & $\mathrm{Rp}$ & 972.000 .000 \\
\hline 6 & Biaya Penyusutan Aset Tetap & $\mathrm{Rp}$ & 120.872 .000 \\
\hline \multicolumn{4}{|c|}{ Biaya Administrasi dan Umum : } \\
\hline 1 & Biaya Perlengkapan Kantor & $\mathrm{Rp}$ & 36.000 .000 \\
\hline 2 & Biaya servis AC & $\mathrm{Rp}$ & 88.216 .000 \\
\hline 4 & Biaya gaji dan tunjangan & $\mathrm{Rp}$ & 2.216 .160 .000 \\
\hline 5 & Tunjangan Hari Raya & $\mathrm{Rp}$ & 235.176 .000 \\
\hline 6 & Biaya Internet & $\mathrm{Rp}$ & 24.000 .000 \\
\hline 7 & Biaya Telepon & $\mathrm{Rp}$ & 6.000 .000 \\
\hline 8 & Biaya BPJS & $\mathrm{Rp}$ & 216.000 .000 \\
\hline 9 & Biaya Rumah Tangga & $\mathrm{Rp}$ & 12.000 .000 \\
\hline 10 & Pajak Bumi dan Bangunan & $\mathrm{Rp}$ & 6.032 .880 \\
\hline 12 & Biaya Penyusutan Aset Tetap & $\mathrm{Rp}$ & 315.659 .050 \\
\hline \multicolumn{2}{|r|}{ Total biaya adm dan pemasaran } & $\mathbf{R p}$ & 5.442 .520 .930 \\
\hline
\end{tabular}

Sumber: perusahaan (data diolah) 


\section{d. Klasifikasi Biaya}

Klasifikasi biaya berdasarkan perilaku ini bertujuan untuk menentukan biaya yang termasuk biaya variabel, biaya tetap, dan biaya semivariabel. Adapun klasifikasi biaya berdasarkan perilaku biaya disajikan sebagai berikut:

Tabel 4. Klasifikasi Biaya

\begin{tabular}{|c|c|c|c|c|}
\hline No & Keterangan & & Total Biaya & Jenis Biaya \\
\hline \multicolumn{5}{|c|}{ Biaya Bahan Baku Langsung : } \\
\hline 1 & Biaya Kertas & $\mathrm{Rp}$ & 3.395 .520 .000 & Variabel \\
\hline 2 & Biaya Tinta & $\mathrm{Rp}$ & 362.718 .000 & Variabel \\
\hline \multicolumn{5}{|c|}{ Biay Overhead Pabrik } \\
\hline 3 & Seng Plat & $\mathrm{Rp}$ & 685.440 .000 & Variabel \\
\hline 4 & Pengawet Koran & $\mathrm{Rp}$ & 16.800 .000 & Variabel \\
\hline 5 & Biaya Gaji Bagian Produksi & $\mathrm{Rp}$ & 3.501 .132 .000 & Tetap \\
\hline 6 & Biaya Honor Tulisan & $\mathrm{Rp}$ & 60.000 .000 & Tetap \\
\hline 7 & Biaya Listrik Bagian Produksi & $\mathrm{Rp}$ & 265.287 .354 & Semi Variabel \\
\hline 8 & Biaya Gaji Reparasi dan Pemeliharaan & $\mathrm{Rp}$ & 201.600 .000 & Tetap \\
\hline 9 & Biaya Bongkar Bahan Baku & $\mathrm{Rp}$ & 10.800 .000 & Variabel \\
\hline 10 & Biaya Servis AC & $\mathrm{Rp}$ & 7.784 .000 & Tetap \\
\hline 11 & Biaya Penyusutan Aset Tetap Bag. Produksi & $\mathrm{Rp}$ & 596.279 .125 & Tetap \\
\hline \multicolumn{5}{|c|}{ Media Online } \\
\hline 10 & Biaya sewa hosting & $\mathrm{Rp}$ & 1.500 .000 & Tetap \\
\hline 11 & Biaya sewa domain & $\mathrm{Rp}$ & 500.000 & Tetap \\
\hline 12 & Biaya Internet & $\mathrm{Rp}$ & 6.000 .000 & Tetap \\
\hline 13 & Biaya Listrik Media Online & $\mathrm{Rp}$ & 16.078 .021 & Semi Variabel \\
\hline 14 & Biaya Gaji Media Online & $\mathrm{Rp}$ & 3.295 .980 .000 & Tetap \\
\hline 15 & Biaya Honor Tulisan & $\mathrm{Rp}$ & 60.000 .000 & Tetap \\
\hline 16 & Biaya Servis AC & $\mathrm{Rp}$ & 5.189 .333 & Tetap \\
\hline 17 & Biaya Amortisasi Aset Tak Berwujud & $\mathrm{Rp}$ & 7.500 .000 & Tetap \\
\hline 18 & Biaya Penyusutan Aset Tetap Media Online & $\mathrm{Rp}$ & 51.079 .250 & Tetap \\
\hline \multicolumn{5}{|c|}{ Biaya Pemasaran } \\
\hline 16 & Biaya Bahan Bakar & $\mathrm{Rp}$ & 696.000 .000 & Variabel \\
\hline 17 & Biaya servis kendaraan & $\mathrm{Rp}$ & 108.000 .000 & Tetap \\
\hline 18 & Biaya gaji dan tunjangan bag. Pemasaran & $\mathrm{Rp}$ & 381.420 .000 & Tetap \\
\hline 19 & Biaya distribusi koran & $\mathrm{Rp}$ & 972.000 .000 & Variabel \\
\hline 20 & Pajak Kendaraan & $\mathrm{Rp}$ & 8.985 .000 & Tetap \\
\hline 21 & Biaya Penyusutan Aset Tetap bag. Pemasaran & $\mathrm{Rp}$ & 120.872 .000 & Tetap \\
\hline \multicolumn{5}{|c|}{ Biaya Administrasi dan Umum } \\
\hline 21 & Biaya Perlengkapan Kantor & $\mathrm{Rp}$ & 36.000 .000 & Tetap \\
\hline 22 & Biaya servis AC & $\mathrm{Rp}$ & 88.216 .000 & Tetap \\
\hline 23 & Biaya gaji dan tunjangan adm dan umum & $\mathrm{Rp}$ & 2.216.160.000 & Tetap \\
\hline 24 & Biaya Internet & $\mathrm{Rp}$ & 24.000 .000 & Tetap \\
\hline 25 & Biaya Telepon & $\mathrm{Rp}$ & 6.000 .000 & Tetap \\
\hline 26 & Tunjangan Hari Raya & $\mathrm{Rp}$ & 235.176 .000 & Tetap \\
\hline 27 & Biaya BPJS & $\mathrm{Rp}$ & 216.000 .000 & Tetap \\
\hline 28 & Biaya Rumah Tangga & $\mathrm{Rp}$ & 12.000 .000 & Tetap \\
\hline 29 & Pajak Bumi dan Bangunan & $\mathrm{Rp}$ & 6.032 .880 & Tetap \\
\hline 30 & Biaya Penyusutan aset tetap bag. adm dan umum & $\mathrm{Rp}$ & 315.659 .050 & Tetap \\
\hline
\end{tabular}

Sumber: data diolah 
Analisis perilaku dapat digunakan sebagai salah satu perangkat bagi manajemen untuk memprediksi biaya yang akan dikeluarkan di masa yang akan datang, menentukan besaran skema biaya beserta pendapatan (Kurniawan, 2017).

\section{e. Pemisahan Biaya Semivariabel}

Metode yang digunakan dalam pemisahan biaya semivariabel adalah metode biaya berjaga (standby cost method). Biaya semivariabel yang akan dipisahkan yaitu biaya listrik bagian produksi dan biaya listrik media online. Dalam menentukan biaya tetap untuk biaya listrik perusahaan ditentukan berdasarkan Peraturan Menteri Energi dan Sumber Daya Mineral Republik Indonesia Nomor 28 Tahun 2016. Berikut ini perhitungan biaya tetap listrik untuk seluruh kantor:

$\begin{array}{lcc}\text { Biaya WBP } & =\text { Rp. } & 28.587 .528 \\ \text { Biaya LWBP } & =\text { Rp. } & 214.406 .460 \\ \text { Pajak Penerangan Jalan } & =\text { Rp. } & 7.289 .820 \\ \text { Biaya Sewa Trafo } & =\text { Rp. } & 11.385 .000 \\ \text { PPN } & =\text { Rp. } & 1.138 .500 \\ \text { Biaya Tetap Listrik } & \text { Rp. } & \mathbf{2 6 2 . 8 0 7 . 3 0 8}\end{array}$

Tabel 5. Pemisahan Biaya Listrik

\begin{tabular}{lrrrr}
\hline \multicolumn{1}{c}{ Keterangan } & \multicolumn{2}{c}{ Biaya Tetap } & \multicolumn{2}{c}{ Biaya Variabel } \\
\hline Produksi & $\mathrm{Rp}$ & 247.789 .747 & $\mathrm{Rp}$ & 17.497 .606 \\
Media Online & $\mathrm{Rp}$ & 15.017 .560 & $\mathrm{Rp}$ & 1.060 .461 \\
\hline Total & $\mathrm{Rp}$ & $\mathbf{2 6 2 . 8 0 7 . 3 0 8}$ & $\mathrm{Rp}$ & $\mathbf{1 8 . 5 5 8 . 0 6 7}$ \\
\hline
\end{tabular}

Sumber: data diolah

\section{f. Identifikasi Pendapatan dan Biaya Relevan}

Semua keputusan berhubungan dengan masa depan, sehingga hanya biaya masa depan yang dapat menjadi relevan dengan keputusan. Biaya dan pendapatan yang relevan untuk pengambilan keputusan tergantung pada konteks keputusan dan alternatif yang tersedia. Adapun identifikasi biaya dan pendapatan relevan dan tidak relevan dapat disajikan sebagai berikut:

\section{Pendapatan Relevan}

Pendapatan merupakan sumber penghasilan yang diperoleh oleh perusahaan dari kegiatan penjualan produk maupun jasa.

Tabel 6. Identifikasi Pendapatan Relevan

\begin{tabular}{llrrrr}
\hline No & \multicolumn{1}{c}{ Keterangan } & & Jumlah & \multicolumn{2}{c}{ Pendapatan Relevan } \\
& & & Relevan & Tidak Relevan \\
\hline 1 & Penjualan Koran & $\mathrm{Rp}$ & 15.552 .000 .000 & $\mathrm{~V}$ & $\mathrm{~V}$ \\
2 & Pendapatan Iklan Koran & $\mathrm{Rp}$ & 3.600 .000 .000 & & $\mathrm{~V}$ \\
3 & Pendapatan Iklan E-Paper & $\mathrm{Rp}$ & 3.600 .000 .000 & & $\mathrm{~V}$ \\
4 & Pendapatan Iklan Media Online & $\mathrm{Rp}$ & 60.000 .000 & $\mathrm{~V}$ & \\
5 & Penjualan E-Paper & $\mathrm{Rp}$ & 144.000 .000 & $\mathrm{~V}$ & \\
6 & Penjualan Seng Plat & $\mathrm{Rp}$ & 60.480 .000 & $\mathrm{~V}$ & \\
\hline
\end{tabular}

Sumber: data diolah 
Penjualan koran, penjualan e-paper, pendapatan iklan media online, dan penjualan seng plat merupakan pendapatan relevan. Pendapatan ini berbeda dari setiap alternatif. Pendapatan iklan koran dan pendapatan iklan e-paper bukanlah pendapatan yang relevan.

\section{Mempertahankan Koran Cetak Tanpa Media Online}

Identifikasi biaya relevan untuk koran cetak dapat disajikan sebagai berikut:

Tabel 7. Identifikasi Biaya Relevan Koran Cetak

\begin{tabular}{|c|c|c|c|c|c|}
\hline \multirow{2}{*}{ No } & \multirow{2}{*}{ Keterangan } & \multirow{2}{*}{\multicolumn{2}{|c|}{ Jumlah }} & \multicolumn{2}{|c|}{ Biaya Relevan } \\
\hline & & & & Relevan & Tidak Relevan \\
\hline 1 & Biaya Kertas & $\mathrm{Rp}$ & 3.395 .520 .000 & $\mathrm{v}$ & \\
\hline 2 & Biaya Tinta & $\mathrm{Rp}$ & 362.718 .000 & v & \\
\hline 3 & Seng Plat & $\mathrm{Rp}$ & 685.440 .000 & v & \\
\hline 4 & Pengawet Koran & $\mathrm{Rp}$ & 16.800 .000 & v & \\
\hline 5 & Biaya Gaji Bagian Produksi : & & & & \\
\hline 6 & Bagian Cetak & $\mathrm{Rp}$ & 201.600 .000 & v & \\
\hline 7 & Bagian Layout & $\mathrm{Rp}$ & 168.000 .000 & & $\mathrm{v}$ \\
\hline 8 & Kabag Percetakan & $\mathrm{Rp}$ & 46.620 .000 & v & \\
\hline 9 & Kasubag Percetakan & $\mathrm{Rp}$ & 45.732 .000 & v & \\
\hline 10 & Reporter & $\mathrm{Rp}$ & 2.264 .400 .000 & & v \\
\hline 11 & Redaktur & $\mathrm{Rp}$ & 498.168 .000 & & v \\
\hline 12 & Redaktur Pelaksana & $\mathrm{Rp}$ & 46.620 .000 & & $\mathrm{v}$ \\
\hline 13 & Sekretaris Redaksi & $\mathrm{Rp}$ & 45.288 .000 & & v \\
\hline 14 & Asisten Redaktur Pelaksana & $\mathrm{Rp}$ & 45.732 .000 & & v \\
\hline 15 & Koordinator Liputan & $\mathrm{Rp}$ & 93.240 .000 & & v \\
\hline 16 & Koordinator Mingguan & $\mathrm{Rp}$ & 45.732 .000 & & $\mathrm{v}$ \\
\hline 17 & Biaya Honor Tulisan & $\mathrm{Rp}$ & 60.000 .000 & & v \\
\hline 18 & Biaya Listrik Bagian Produksi & $\mathrm{Rp}$ & 265.287 .354 & v & \\
\hline \multirow[t]{3}{*}{19} & Biaya Servis AC & & & & \\
\hline & Ruangan Produksi & $\mathrm{Rp}$ & 2.594 .667 & v & \\
\hline & Ruangan Redaktur & $\mathrm{Rp}$ & 5.189 .333 & & $\mathrm{v}$ \\
\hline 20 & Biaya Gaji Reparasi dan Pemeliharaan & $\mathrm{Rp}$ & 201.600 .000 & $\mathrm{v}$ & \\
\hline 21 & Biaya Bongkar Bahan Baku & $\mathrm{Rp}$ & 10.800 .000 & v & \\
\hline 22 & Biaya Penyusutan Aset Tetap & $\mathrm{Rp}$ & 596.279 .125 & & $\mathrm{v}$ \\
\hline
\end{tabular}

Sumber: data diolah

Dapat dilihat pada tabel 7 biaya yang dicentang pada kolom relevan merupakan biaya relevan, karena biaya ini akan hilang jika produksi koran cetak dihentikan. Biaya penyusutan aset tetap merupakan biaya tertanam, biaya tertanam merupakan biaya tidak relevan. Biaya gaji untuk bagian yang dicentang pada kolom tidak relevan merupakan biaya tidak relevan. Karena biaya ini akan tetap muncul jika koran cetak dihentikan produksinya. 


\section{Menghentikan Koran Cetak dan Menggati ke Media Online}

Adapun biaya media online yang dikeluarkan oleh perusahaan selama satu tahun adalah sebagai berikut:

Tabel 8. Identifikasi Biaya Relevan Media Online

\begin{tabular}{rlrrrr}
\hline \multirow{2}{*}{ No Keterangan } & \multicolumn{2}{c}{ Jumlah } & \multicolumn{2}{c}{ Biaya Relevan } \\
& \multicolumn{1}{c}{ Relevan } & Tidak Relevan \\
\hline 1 & Biaya sewa hosting & $\mathrm{Rp}$ & 1.500 .000 & $\mathrm{~V}$ & \\
2 & Biaya sewa domain & $\mathrm{Rp}$ & 500.000 & $\mathrm{~V}$ & \\
3 & Biaya Internet & $\mathrm{Rp}$ & 6.000 .000 & $\mathrm{~V}$ & \\
4 & Biaya Listrik Media Online & $\mathrm{Rp}$ & 16.078 .021 & $\mathrm{~V}$ & \\
5 & Biaya Gaji Media Online : & & & & $\mathrm{V}$ \\
6 & Bagian IT Online & $\mathrm{Rp}$ & 88.800 .000 & $\mathrm{~V}$ & $\mathrm{~V}$ \\
7 & Bagian Layout & $\mathrm{Rp}$ & 168.000 .000 & & $\mathrm{~V}$ \\
8 & Reporter & $\mathrm{Rp}$ & 2.264 .400 .000 & & $\mathrm{~V}$ \\
9 & Redaktur & $\mathrm{Rp}$ & 498.168 .000 & & $\mathrm{~V}$ \\
10 & Redaktur Pelaksana & $\mathrm{Rp}$ & 46.620 .000 & & $\mathrm{~V}$ \\
11 & Sekretaris Redaksi & $\mathrm{Rp}$ & 45.288 .000 & & $\mathrm{~V}$ \\
12 & Asisten Redaktur Pelaksana & $\mathrm{Rp}$ & 45.732 .000 & & $\mathrm{~V}$ \\
13 & Koordinator Liputan & $\mathrm{Rp}$ & 93.240 .000 & & $\mathrm{~V}$ \\
14 & Koordinator Mingguan & $\mathrm{Rp}$ & 45.732 .000 & & $\mathrm{~V}$ \\
15 & Biaya Servis AC & $\mathrm{Rp}$ & 5.189 .333 & & $\mathrm{~V}$ \\
16 & Biaya Honor Tulisan & $\mathrm{Rp}$ & 60.000 .000 & & $\mathrm{~V}$ \\
17 & Biaya Amortisasi Aset Tidak Berwujud & $\mathrm{Rp}$ & 7.500 .000 & & \\
18 & Biaya Penyusutan Aset Tetap Media Online & $\mathrm{Rp}$ & 51.079 .250 & & \\
\hline
\end{tabular}

Sumber: data diolah

Pada tabel 8 dapat dilihat biaya sewa hosting, biaya sewa domain, biaya internet, biaya gaji IT online merupakan biaya relevan karena biaya ini akan muncul ketika perusahaan memutuskan untuk mengganti ke media online dan menghentikan koran cetak. Sementara itu, biaya gaji yang dicentang pada kolom tidak relevan merupakan biaya tidak relevan, karena biaya ini akan tetap muncul diantara beberapa alternatif keputusan.

\section{Biaya Pemasaran}

Adapun biaya pemasaran yang dikeluarkan oleh perusahaan selama satu tahun adalah sebagai berikut:

Tabel 9. Identifikasi Biaya Relevan Pemasaran

\begin{tabular}{llrrrc}
\hline \multirow{2}{*}{ No Keterangan } & \multicolumn{2}{c}{ Jumlah } & \multicolumn{2}{c}{ Biaya Relevan } \\
& & & Relevan & Tidak Relevan \\
\hline 1 & Biaya Bahan Bakar & $\mathrm{Rp}$ & 696.000 .000 & $\mathrm{~V}$ & \\
2 & Biaya servis kendaraan & $\mathrm{Rp}$ & 108.000 .000 & $\mathrm{~V}$ & \\
3 & Biaya gaji dan tunjangan Bag. Pemasaran : & & & & $\mathrm{V}$ \\
4 & Kabag Pemasaran & $\mathrm{Rp}$ & 46.620 .000 & & $\mathrm{~V}$ \\
5 & Karyawan & $\mathrm{Rp}$ & 133.200 .000 & & $\mathrm{~V}$ \\
6 & Sopir & $\mathrm{Rp}$ & 201.600 .000 & $\mathrm{~V}$ & $\mathrm{~V}$ \\
7 & Pajak Kendaraan & $\mathrm{Rp}$ & 8.985 .000 & $\mathrm{~V}$ & $\mathrm{~V}$ \\
8 & Biaya distribusi koran & $\mathrm{Rp}$ & 972.000 .000 & $\mathrm{~V}$ & \\
9 & Biaya Penyusutan Aset Tetap bag. Pemasaran & $\mathrm{Rp}$ & 120.872 .000 & & \\
\hline
\end{tabular}

Sumber: data diolah 
Biaya bahan bakar, biaya servis kendaraan, biaya gaji sopir, pajak kendaraan, dan biaya distribusi koran merupakan biaya relevan. Biaya ini akan hilang jika perusahaan menghentikan memproduksi koran cetak.

\section{Biaya Administrasi dan Umum}

Adapun biaya administrasi dan umum yang dikeluarkan oleh perusahaan selama satu tahun adalah sebagai berikut:

Tabel 10. Identifikasi Biaya Relevan Biaya Administrasi dan Umum

\begin{tabular}{|c|c|c|c|c|c|}
\hline \multirow{2}{*}{ No } & \multirow{2}{*}{ Keterangan } & \multirow{2}{*}{\multicolumn{2}{|c|}{ Jumlah }} & \multicolumn{2}{|c|}{ Biaya Relevan } \\
\hline & & & & Relevan & Tidak Relevan \\
\hline 1 & Biaya Perlengkapan Kantor & $\mathrm{Rp}$ & 36.000 .000 & & V \\
\hline 2 & Biaya servis AC & $\mathrm{Rp}$ & 88.216 .000 & & v \\
\hline 4 & Biaya gaji dan tunjangan adm dan umum & $\mathrm{Rp}$ & 2.216 .160 .000 & & $\mathrm{v}$ \\
\hline 5 & Biaya Internet & $\mathrm{Rp}$ & 24.000 .000 & & $\mathrm{v}$ \\
\hline 6 & Biaya Telepon & $\mathrm{Rp}$ & 6.000 .000 & & v \\
\hline 7 & Biaya BPJS & $\mathrm{Rp}$ & 216.000 .000 & & v \\
\hline 8 & Tunjangan Hari Raya & $\mathrm{Rp}$ & 235.176 .000 & & $\mathrm{v}$ \\
\hline 9 & Pajak Bumi dan Bangunan & $\mathrm{Rp}$ & 6.032 .880 & & $\mathrm{v}$ \\
\hline 10 & Biaya Rumah Tangga & $\mathrm{Rp}$ & 12.000 .000 & & $\mathrm{v}$ \\
\hline 11 & Biaya Penyusutan adm dan umum & $\mathrm{Rp}$ & 315.659 .050 & & v \\
\hline
\end{tabular}

Sumber: data diolah

Biaya administrasi dan umum merupakan biaya tidak relevan, karena biaya ini akan tetap muncul dan memiliki jumlah yang sama ketika perusahaan memilih salah satu diantara alternatif keputusan.

\section{Biaya dan Manfaat Relevan untuk Ketiga Alternatif Keputusan}

Setelah melakukan identifikasi biaya relevan dan tidak relevan, biaya yang tergolong ke dalam biaya relevan diambil sebagai pertimbangan untuk pengambilan keputusan, dan biaya yang tidak relevan dieliminasi. Langkah selanjutnya adalah menghitung total keuntungan relevan untuk ketiga alternatif keputusan. Perhitungan laba rugi yang relevan menggunakan format laporan laba rugi variable costing. Apabila perusahaan memproduksi koran cetak saja total biaya relevan yaitu Rp. 7.221.297.020, maka total keuntungan relevan yang dihasilkan adalah $\mathrm{Rp}$. 8.391.182.980. Media online memiliki total biaya relevan sebesar Rp. 112.878.021, maka total keuntungan relevan yang dihasilkan adalah Rp. 91.121.979. Serta mempertahankan koran cetak dan meneruskan media online total biaya sebesar Rp. 7.334.175.042, maka total keuntungan relevan yang dihasilkan adalah sebesar Rp. 8.482.304.958. 
Tabel 11. Total Keuntungan Relevan dari Ketiga Alternatif Keputusan

\begin{tabular}{|c|c|c|c|c|c|c|c|c|}
\hline \multirow[t]{2}{*}{ Keterangan } & \multicolumn{2}{|c|}{ Koran Cetak } & $\begin{array}{l}\text { Keterangan } \\
\text { Pendapatan }\end{array}$ & \multicolumn{2}{|c|}{ Media Online } & \multirow[t]{2}{*}{ Keterangan } & \multicolumn{2}{|c|}{$\begin{array}{c}\text { Koran Cetak dan Media } \\
\text { Online }\end{array}$} \\
\hline & $\mathrm{Rp}$ & 15.612 .480 .000 & Pendapatan & $\mathrm{Rp}$ & 204.000 .000 & & $\mathrm{Rp}$ & 15.816 .480 .000 \\
\hline Biaya Variabel & & & Biaya Variabel & & & Biaya Variabel & & \\
\hline Biaya Produksi Variabel : & & & Biaya Listrik Media Online & $\mathrm{Rp}$ & 1.060 .461 & Biaya Produksi Variabel : & & \\
\hline Biaya Tinta Hitam & $\mathrm{Rp}$ & 179.550 .000 & & & & Biaya Tinta Hitam & $\mathrm{Rp}$ & 179.550 .000 \\
\hline Biaya Tinta Giant & $\mathrm{Rp}$ & 65.664 .000 & & & & Biaya Tinta Giant & $\mathrm{Rp}$ & 65.664 .000 \\
\hline Biaya Tinta Yellow & $\mathrm{Rp}$ & 58.752 .000 & & & & Biaya Tinta Yellow & $\mathrm{Rp}$ & 58.752 .000 \\
\hline Biaya Tinta Magenta & $\mathrm{Rp}$ & 58.752 .000 & & & & Biaya Tinta Magenta & $\mathrm{Rp}$ & 58.752 .000 \\
\hline Seng Plat & $\mathrm{Rp}$ & 685.440 .000 & & & & Seng Plat & $\mathrm{Rp}$ & 685.440 .000 \\
\hline Biaya Listrik Bagian Produksi & $\mathrm{Rp}$ & 17.497 .606 & & & & Biaya Listrik Bagian Produksi & $\mathrm{Rp}$ & 17.497 .606 \\
\hline Biaya Bongkar Bahan baku & $\mathrm{Rp}$ & 10.800 .000 & & & & Biaya Bongkar Bahan baku & $\mathrm{Rp}$ & 10.800 .000 \\
\hline Biaya Pemasaran Variabel : & & & & & & Biaya Listrik Media Online & $\mathrm{Rp}$ & 1.060 .461 \\
\hline Biaya Bahan Bakar & $\mathrm{Rp}$ & 696.000 .000 & & & & Biaya Pemasaran Variabel : & & \\
\hline \multirow{2}{*}{ Biaya Distribusi Koran } & $\mathrm{Rp}$ & 972.000 .000 & & & & Biaya Bahan Bakar & $\mathrm{Rp}$ & 696.000 .000 \\
\hline & & & & & & Biaya Distribusi Koran & $\mathrm{Rp}$ & 972.000 .000 \\
\hline Total Biaya Variabel & $\mathrm{Rp}$ & 6.156 .775 .606 & Total Biaya Variabel & $\mathrm{Rp}$ & 1.060 .461 & Total Biaya Variabel & $\mathrm{Rp}$ & 6.157.836.067 \\
\hline Margin Kontribusi & $\mathrm{Rp}$ & 9.455 .704 .394 & Margin Kontribusi & $\mathrm{Rp}$ & 202.939 .539 & Margin Kontribusi & $\mathrm{Rp}$ & 9.658 .643 .933 \\
\hline Biaya Produksi Tetap : & & & Biaya Sewa Hosting & $\mathrm{Rp}$ & 1.500 .000 & Biaya Produksi Tetap : & & \\
\hline Biaya Gaji Bagian Produksi & $\mathrm{Rp}$ & 293.952 .000 & Biaya Sewa Domain & $\mathrm{Rp}$ & 500.000 & Biaya Gaji Bagian Produksi & $\mathrm{Rp}$ & 293.952 .000 \\
\hline Biaya Listrik Bagian Produksi & $\mathrm{Rp}$ & 247.789 .747 & Biaya Internet & $\mathrm{Rp}$ & 6.000 .000 & Biaya Listrik Bagian Produksi & $\mathrm{Rp}$ & 247.789 .747 \\
\hline Biaya gaji reparasi dan pemeliharaan & $\mathrm{Rp}$ & 201.600 .000 & Biaya Gaji Media Online & $\mathrm{Rp}$ & 88.800 .000 & Biaya reparasi dan pemeliharaan & $\mathrm{Rp}$ & 201.600 .000 \\
\hline Biaya Servis AC & $\mathrm{Rp}$ & 2.594 .667 & Biaya Listrik Bagian Online & $\mathrm{Rp}$ & 15.017 .560 & Biaya Servis AC & $\mathrm{Rp}$ & 2.594 .667 \\
\hline Biaya Pemasaran Tetap : & & & & & & Biaya Sewa Hosting & $\mathrm{Rp}$ & 1.500 .000 \\
\hline Biaya Gaji Sopir & $\mathrm{Rp}$ & 201.600 .000 & & & & Biaya Sewa Domain & $\mathrm{Rp}$ & 500.000 \\
\hline Biaya Servis Kendaraan & $\mathrm{Rp}$ & 108.000 .000 & & & & Biaya Internet & $\mathrm{Rp}$ & 6.000 .000 \\
\hline \multirow[t]{6}{*}{ Pajak Kendaraan } & $\mathrm{Rp}$ & 8.985 .000 & & & & Biaya Gaji Online & "Rp & 88.800 .000 \\
\hline & & & & & & Biaya Listrik Bagian Online & $\mathrm{Rp}$ & 15.017 .560 \\
\hline & & & & & & Biaya Pemasaran Tetap : & & \\
\hline & & & & & & Biaya Gaji Sopir & $\mathrm{Rp}$ & 201.600 .000 \\
\hline & & & & & & Biaya Servis Kendaraan & $\mathrm{Rp}$ & 108.000 .000 \\
\hline & & & & & & Pajak Kendaraan & $\mathrm{Rp}$ & 8.985 .000 \\
\hline Total Biaya Tetap & $\mathrm{Rp}$ & 1.064.521.414 & Total Biaya Tetap & $\mathrm{Rp}$ & 111.817 .560 & Total Biaya Tetap & $\mathrm{Rp}$ & 1.176.338.974 \\
\hline Total Keuntungan Relevan & $\mathrm{Rp}$ & 8.391 .182 .980 & Total Keuntungan Relevan & $\mathrm{Rp}$ & 91.121 .979 & Total Keuntungan Relevan & $\mathrm{Rp}$ & 8.482 .304 .958 \\
\hline
\end{tabular}

Sumber: data diolah 


\section{Rasio Profitabilitas}

Rasio profitabilitas merupakan rasio yang digunakan untuk mengukur kemampuan perusahaan dalam menghasilkan laba dari aktivitas normal bisnisnya. Penelitian ini menggunakan rasio operasi. Rasio ini berguna bagi analisis beban dalam perusahaan atau antar perusahaan dan dapat dipandang sebagai langkah tambahan dalam analisis common-size atas laba (Wild dkk, 2005). Rumus analisis rasio operasi adalah:

$$
\text { Analisis Rasio Operasi }=\frac{\text { Total beban }}{\text { Total pendapatan }}
$$

Berikut ini adalah rasio profitabilitas yang diukur menggunakan rasio operasi untuk ketiga alternatif keputusan:

Tabel 12. Rasio Profitabilitas

\begin{tabular}{clc}
\hline No & \multicolumn{1}{c}{ Keterangan } & Rasio \\
\hline 1 & Mempertahankan koran cetak tanpa media online & $46 \%$ \\
2 & Menghentikan koran cetak dan mengganti ke media online & $55 \%$ \\
3 & Mempertahankan koran cetak dan meneruskan media online & $46 \%$ \\
\hline
\end{tabular}

Sumber: data diolah

Berdasarkan rasio profitabilitas dengan menggunakan analisis rasio operasi, mempertahankan koran cetak memiliki rasio operasi sebesar 46\%, mengganti ke media online memiliki rasio operasi sebesar 55\%, atau tetap mempertahankan koran cetak dan meneruskan media online juga memiliki rasio operasi sebesar $46 \%$. Total biaya relevan dari mengganti ke media online lebih kecil karena pengeluaran biaya media online tidak sebesar koran cetak. Persentase rasio operasi akan tinggi apabila total biaya relevan rendah. Jika total biaya relevan tinggi maka persentase rasio operasi yang didapat akan rendah.

\section{Faktor-Faktor Non Keuangan yang Menjadi Pertimbangan dalam Pengambilan Keputusan Taktis}

Pengambilan keputusan taktis membutuhkan faktor-faktor non keuangan dalam mempertimbangkan pengambilan keputusan. Faktor-faktor kualitatif dapat disajikan sebagai berikut:

a. Faktor-Faktor non Keuangan yang Menjadi Pertimbangan dalam Mempertahankan Koran Cetak

Adapun faktor-faktor non keuangan yang menjadi pertimbangan dalam mempertahankan koran cetak sebagai berikut:

1. Pendapatan Koran Cetak Cukup Besar

Pendapatan dari penjualan koran cukup besar dibandingkan dengan media online. Pendapatan koran cetak tetap menjadi pemasukan pendapatan bagi perusahaaan.

2. Pembaca Fanatik

Koran cetak merupakan salah satu bacaan bagi masyarakat untuk mendapatkan informasi. Keberadaan koran cetak yang telah ada sejak lama, mendatangkan pembaca berita yang fanatik terhadap pemerolehan informasi atau berita melalui koran cetak. 
3. Hubungan dengan Karyawan

Perusahaan mempertimbangkan karyawan sebagai alasan untuk tetap mempertahankan koran cetak. Perekrutan karyawan dilakukan sesuai dengan kebutuhan perusahaan. Tetapi jika tidak efektif lagi bagi perusahaan dari segi pembiayaan, dan membuat perusahaan tidak stabil maka karyawan otomatis dikurangi atau di PHK.

4. Nama Besar Harian Umum $X$

Koran Harian Umum X merupakan salah satu media cetak terbesar di Sumatera Barat. Mendirikan sebuah surat kabar bukan persoalan yang mudah bagi perusahaan. Pada saat ini, perusahaan media cetak sudah banyak bermunculan tetapi tidak banyak yang dapat bertahan. Perusahaan menganggap bahwa nama besar sebuah surat kabar sangat penting untuk tetap dipertahankan.

5. Melakukan efisiensi

Pemilik dan manajemen menganggap jika koran cetak masih menguntungkan dari segi bisnis, maka akan tetap dipertahankan walaupun terjadi penurunan produksi koran.

b. Faktor-Faktor non Keuangan yang Menjadi Pertimbangan dalam Meneruskan Media Online

Adapun faktor-faktor non keuangan yang menjadi pertimbangan dalam meneruskan media online sebagai berikut:

1. Perkembangan Teknologi

Perkembangan teknologi dan perubahan minat baca masyarakat ke media online, membuat beberapa perusahaan mulai mendirikan bisnis media online. Mendirikan bisnis media online merupakan suatu kesempatan dan tantangan bagi perusahaan media cetak untuk menyajikan informasi melalui media online.

2. Menarik Hati Pembaca

Meneruskan media online merupakan strategi yang digunakan oleh perusahaan untuk menarik hati pembaca.

3. Pembaca Tidak Hanya Lokal Bahkan Internasional

Keputusan perusahaan untuk merambat ke bisnis media online mendatangkan banyak keuntungan bagi perusahaan. Keuntungan yang diperoleh tentunya ada pendapatan yang diperoleh oleh perusahaan. Perusahaan juga mendapatkan keuntungan yaitu bertambahnya jumlah pembaca berita yang disediakan oleh perusahaan.

4. Perusahaan Dapat Meningkatkan Pendapatan Iklan

Semakin terkenal media online yang dimiliki oleh perusahaan maka pendapatan iklan akan semakin meningkat. Pihak yang ingin memasang iklan pada perusahaan akan semakin tertarik jika media online sudah banyak diminati.

5. Media Online Mengeluarkan Biaya Yang Lebih Kecil 
Biaya yang dikeluarkan oleh perusahaan untuk media online tidak sebesar koran cetak. Koran cetak membutuhkan pembelian tinta, dan kertas setiap hari, dan pengeluarannya cukup besar bagi perusahaan. Koran cetak juga membutuhka kendaraan untuk mendistribusikannya, sementara media online tidak membutuhkan itu.

\section{Membuat Keputusan}

Berdasarkan analisis total biaya relevan dan rasio profitabilitas yang diukur dengan rasio operasi, keputusan yang dapat direkomendasikan bagi perusahaan adalah mengganti ke media online. Berdasarkan hasil wawancara manajemen berpendapat bahwa dari sisi bisnis, media online lebih menguntungkan dibandingkan dengan koran cetak. Perusahaan tidak perlu mengeluarkan biaya yang besar untuk pembelian kertas dan tinta. Perusahaan juga tidak membutuhkan kendaraan untuk melakukan pendistribusian.

Berdasarkan analisis pengambilan keputusan taktis: tetap mempertahankan koran cetak atau mengganti ke media online dapat dibuat sebuah model sebagai berikut:

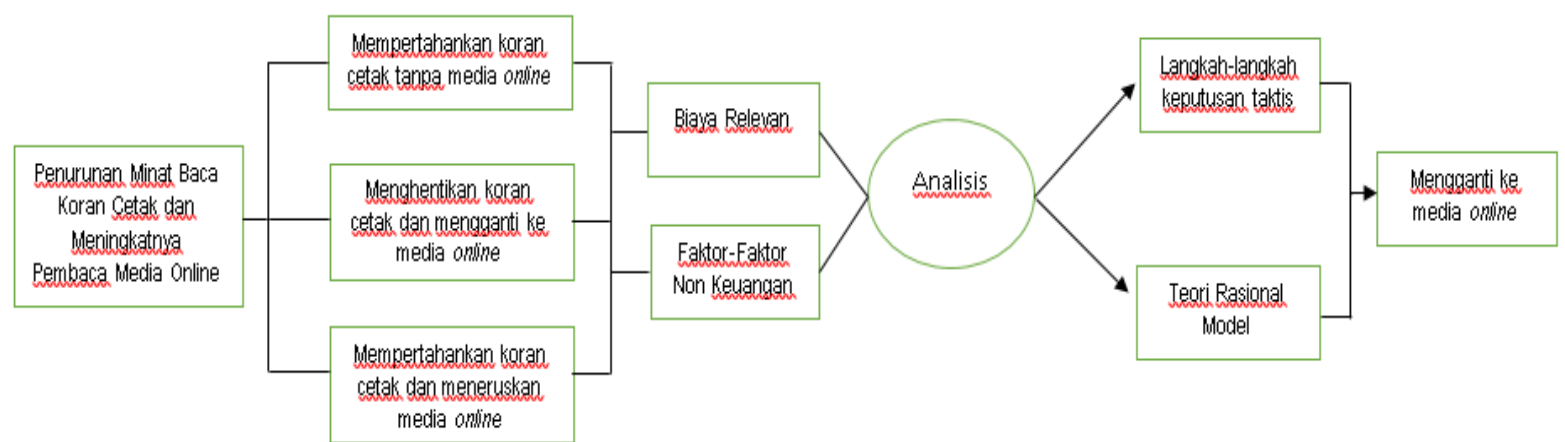

Gambar 2. Model pengambilan keputusan taktis

Model pengambilan keputusan taktis ini merupakan pengambangan dari model proses pengambilan keputusan yang dibuat oleh Schoenfeld. Pada tahap awal dilakukan identifikasi masalah yang dihadapi oleh perusahaan yaitu penurunan minat baca koran cetak dan meningkatnya pembaca media online. Langkah selanjutnya adalah mengidentifikasi beberapa alternatif keputusan, sebagai bahan pertimbangan pengambilan keputusan manajemen melihat dari sisi biaya relevan dan faktor-faktor non keuangan. Selanjutnya dilakukan analisis dengan menggunakan langkah-langkah pengambilan keputusan taktis dan teori rasional model. Langkah terakhir adalah membuat keputusan setelah analisis dilakukan, yaitu mengganti ke media online.

\section{Kesimpulan}

Berdasarkan hasil analisis pengambilan keputusan taktis: tetap mempertahankan koran cetak, mengganti ke media online, atau tetap mempertahankan koran cetak dan meneruskan media online maka dapat ditarik kesimpulan sebagai berikut:

a. Total biaya relevan mempertahankan koran cetak sebesar Rp. 7.221.297.020 maka total keuntungan relevan yang diperoleh sebesar Rp. 8.391.182.980. Sementara itu, total biaya relevan mengganti ke media online adalah sebesar Rp. 112.878.021 maka total keuntungan relevan yang diperoleh adalah 
sebesar Rp. 91.121.979. Mempertahankan koran cetak dan meneruskan media online memilki total biaya relevan sebesar Rp. 7.334.175.042 maka total keuntungan relevan yang diperoleh adalah sebesar Rp. 8.482.304.958.

b. Rasio operasi alternatif pertama dan alternatif ketiga adalah masing-masing sebesar $46 \%$, sedangkan rasio operasi alternatif kedua adalah sebesar 55\%.

c. Keputusan yang dapat direkomendasikan bagi perusahaan untuk ke depannya adalah mengganti ke media online. Media online lebih menguntungkan dari segi biaya, karena media online ini tidak membutuhkan biaya sebesar koran cetak.

\section{Saran}

Perusahaan dapat menerapkan analisis biaya relevan untuk pengambilan keputusan. Perusahaan disarankan mengganti ke media online sebab dari segi bisnis lebih menguntungkan bagi perusahaan. Mengganti ke media online memiliki total biaya yang kecil dibandingkan dengan koran cetak.

\section{Ucapan Terima Kasih}

Penulis mengucapkan terima kasih kepada Allah SWT, kedua orang tua, keluarga besar Harian Umum X, teman-teman peneliti yaitu kurniawati putri, armel yentifa, dita maretha rissi, dan dosen jurusan Akuntansi Politeknik Negeri Padang. Penulis tidak bisa menyelesaikan jurnal ini tanpa adanya bantuan dari orang-orang terdekat penulis. Terima kasih kepada keluarga besar Harian Umum X yang telah memberikan izin kepada penulis melaksanakan penelitian, sehingga jurnal ini dapat penulis selesaikan. Dan terakhir penulis juga mengucapkan terima kasih kepada Pusat Penelitian dan Pengabdian Kepada Masyarakat Politeknik Negeri Padang yang telah mendanai penelitian ini.

\section{Referensi}

[1] Dharapak, Charles. 2013. Daftar Media Cetak Amerika yang Gulung Tikar diunduh https://dunia.tempo.co/read/502699/daftar-media-cetak-amerika-yanggulung-tikar diakses 23 Maret 2018 pukul 09:12 WIB

[2] Hansen, Don R dan Maryanne M. Mowen. 2009. Akuntansi Manajerial. Buku kedua. Edisi kedepalan. Jakarta: Erlangga

[3] Lunenburg, Fred C. 2010. The Decision Making Process. National Forum Of Educational Administration And Supervision Journal Volume 27, Number 4

[4] Piliang, Nandra F. 2017. Ketua Dewan Pers : Pembaca Media Cetak Turun 30 Persen, Media Online Naik 500 Perse diunduh https://www.riaumandiri.id/read/detail/52890/ketua-dewan-pers:pembaca-media-cetak-turun-30-persen,-media-online-naik-500-persen.html

[5] Prihatin, Intan Umbari. 2015. Media Cetak Indonesia Bertumbangan, Ada Indikasi Sindrom Menular diiunduh https://www.google.co.id/amp/m.merdeka.com/amp/peristiwa/media- 
cetak-indonesia-bertumbangan-ada-indikasi-sindrom-menular-bisnis-mediamassa indonesia.html.

[6] Samryn. 2002. Akuntansi Manajerial Suatu Pengantar. Jakarta: PT RajaGrafindo Persada.

[7] Simamora, Hery. 2012. Akuntansi Manajemen. Edisi III. Jakarta: Start Gade Publisher.

[8] Siregar, Suripto dkk. 2013. Akuntansi Manajemen. Jakarta: Salemba Empat

[9] Turpin, SM, MA Marais. 2004. Decision-making: Theory and Practice. Orion Vol. 20, pp, 143-160. 